\title{
Perancangan Aplikasi Perpustakaan Berbasis Web pada SMK Negeri 1 Rangkasbitung
}

\author{
Zafira Salsabilah $^{1}$ dan Yulianti $^{2}$ \\ ${ }^{1,2}$ Teknik Informatika, Fakultas Teknik, Universitas Pamulang, Tangerang Selatan, Indonesia \\ e-mail: $\left\{{ }^{1}\right.$ salsabilaza1111, ${ }^{2}$ yulianti.saifudin $\} @$ gmail.com
}

\begin{abstract}
The school library is one of supporting that could achieve the quality of education. It was because the library could be a source of learning in the school. Management of data processing, lending, and returning of library books could take a lot of fees and times. It was because using a ledger. Besides, the students having difficulties in order to get the books. It was because there is no technology information that provide the search engine toward a books. This research was focus on the library information system. The objective of this research were to facilitate officer in managing the library data and to make the students easy to find the books. This library application is website-based which is develop by using the PHP as programming language while MySQL as database management system. The method that used to conduct the data were structured interview, literature study, and observation which regard to the school library in making a library application. This study gives the result in the usability aspect the percentage is $79,5 \%$, its mean that the library application could facilitate officer in processing data collection, borrowing and returning library books, moreover, the students could search the book easily.
\end{abstract}

Keywords: Library, PHP, MySQL, Usability

\section{Pendahuluan}

Perpustakaan sekolah adalah perpustakaan yang berada pada lembaga pendidikan sekolah sebagai pusat sumber belajar mengajar. Atas pernyataan tersebut, beberapa tugas perpustakaan sekolah adalah mengelola datadata perpustkaan, memberikan layanan pemimjaman buku, menyediakan tempat membaca dan mengembangkan agar mudah dikontrol dan diakses olah anggota perpustkaan. Menyediakan sumber-sumber referensi untuk menambah pengetahuan siswa dan guru. Mendidik siswa agar dapat mencari dan mengumpulkan informasi (referensi) secara mandiri (Hartono, 2016).

Banyaknya tugas perpustakaan yang harus dilaksanakan, ternyata tidak sebanding dengan sarana dan prasarana yang disediakan. Pada perpustakaan sekolah SMK Negeri 1 Rangkasbitung, diketahui bahwa sistem yang sedang berjalan di perpustakaan sekolah tersebut masih sederhana karena belum terkomputerisisasi dan menggunakan media buku induk sebagai media penyimpanannya. Permasalahan lainnya adalah anggota kesulitan dalam pencarian buku di rak karena belum tersedianya katalog buku yang bisa memberikan informasi mengenai ketersediaan buku di perpustakaan (Hendrianto, 2014).

Untuk mengatasi masalah tersebut, dibuat suatu aplikasi yang menyediakan penyimpanan data secara digital agar dapat mempercepat proses pengolahan data perpustakaan menjadi lebih cepat. Selain itu juga dibutuhkan aplikasi yang menyediakan OPAC (Online Pubilc Access Catalogue) yang dapat membantu siswa dalam mencari informasi koleksi buku (Utami, 2013).

Model pengembangan perangkat lunak yang diusulkan untuk pembuatan aplikasi perpustakaan ini adalah model Waterfall karena kebutuhan software sudah jelas dan telah diidentikasi di awal. Selain itu, model Waterfall menggunakan tahapan terstruktur secara runut dari awal hingga akhir. Model Waterfall lebih mudah diikuti dan dikontrol karena dilakukan dengan mengikuti tahap pengembangan secara berurutan, yaitu analisa, desain, pengkodean, pengujian, dan pemeliharaan (Usada \& Ariyanto, 2012).

\section{Dasar Teori}

\subsection{Kajian Penelitian Relevan}

Pertama, penelitian yang dilakukan oleh Hendrianto (Hendrianto, 2014) yang menyatakan bahwa sistem sebelumnya memiliki 
beberapa masalah, yaitu pelayanan petugas perpustakaan masih lambat karena masih dilakukan secara konvensional menggunakan buku peminjaman. Hasil penelitian dan pengembangan sistem menunjukkan bahwa aplikasi perpustakaan yang baru dapat meningkatkan layanan dan kinerja petugas dalam mengelola administrasi, serta mempercepat transaksi peminjaman dan pengembalian buku. Persamaan penelitian terdahulu dengan yang saya teliti terletak pada tujuan pembuatan aplikasi, yaitu untuk membantu petugas perpustakaan agar proses pengolahan data perpustakaan menjadi lebih cepat. Persamaan lainnya adalah aplikasi bisa diakses oleh siswa dan pengunjung lain untuk mencari koleksi buku. Sedangkan perbedaannya terletak pada jumlah informasi yang disediakan. Pada aplikasi yang dibuat pada penelitian terdahulu aplikasi hanya menyediakan layanan pencarian buku untuk anggota. Sedangkan peneliti sendiri meningkatkan layanan tersebut dengan menyediakan layanan penyimpanan informasi setelah buku tersebut dicari. Layanan lainnya adalah anggota dapat melihat daftar buku yang pernah dipinjamnya dengan adanya riwayat peminjaman.

Kedua, penelitian yang dilakukan oleh Usada dan Ariyanto (Usada \& Ariyanto, 2012) yang menyatakan bahwa pada sistem sebelumnya menggunakan satu komputer yang digunakan secara bergantian sehingga harus antri. Pada penelitian ini diusulkan pengembangan sistem dengan menggunakan jaringan lokal untuk menghubungkan beberapa komputer yang terinstal aplikasi perpustakaan sehingga bisa memberikan layanan lebih banyak. Hasil penelitian ini menunjukkan bahwa siswa bisa mencari dan mengakses data bukubuku yang ada di perpustakaan secara bersamasama. Petugas diberikan kemudahan dalam mengelola data buku-bukunya. Penelitian terdahulu dan penelitian yang saya lakukan terletak pada tujuan pembuatan aplikasi, yaitu untuk siswa dapat mengakses informasi buku dan memudahkan petugas mengolah data perpustakaan. Sedangkan perbedaannya terletak pada jenis jaringan yang digunakan. Pada penelitian terdahulu digunakan jaringan LAN (Local Area Network) sehingga aplikasi hanya bisa digunakan di lingkungan sekolah saja, sedangkan peneliti sendiri meningkatkannya sehingga aplikasi bisa diakses di mana saja, yaitu menggunakan jaringan internet.

\subsection{Model Pengembangan Waterfall}

Untuk pengembangan perangkat lunak yang telah didefinisikan persyaratannya dengan detail di awal dapat menerapkan model Waterfall agar menghasilkan perangkat lunak yang matang. Model pengembangan Waterfall memiliki tahapan-tahapan sebagai berikut (Shalahuddin \& Sukamto, 2014):

1) Analisis Kebutuhan

Tahap analisis kebutuhan adalah tahapan saat peneliti menentukan target mengenai apa dan siapa pengguna sistem, untuk apa sistem digunakan dan bagaimana penetapan penyelesaian masalah berdasarkan kegunaan sistem. Tahap ini adalah awal mulainya pengembangan, di mana sistem dianalisis terlebih dahulu terhadap hal-hal yang dibutuhkan dalam pengembangan seperti komponen pendukung, hardware yang diperlukan, bahasa pemrograman yang digunakan, dan lain-lain.

2) Desain Sistem

Desain sistem adalah tahapan saat pelaku pengembangan mencoba merekayasa perilaku sistem menggunakan simbolsimbol dan gambar yang mempresentasikan bagaimana komponenkomponen dalam sistem saling berhubungan.

3) Implementasi Kode

Tahapan ini merupakan tindakan penulisan kode pemrograman berdasarkan acuan dari hasil tahapan sebelumnya.

4) Pengujian

Tahap ini adalah tahap saat hasil perangkat lunak diuji coba agar diketahui kesalahan-kesalahan yang terjadi berdasarkan hasil perangkat lunak di mana selanjutnya perlu diperbaiki dan disempurnakan sebelum perangkat lunak tersebut masuk ke dalam tahap pemeliharaan.

5) Pemeliharaan

Tahapan ini adalah tahap saat pengembang melakukan pemeliharaan teratur pada perangkat lunak atau sistem tersebut digunakan.

Berdasarkan penjelasan di atas dapat disimpulkan bahwa model waterfall cocok digunakan untuk pembuatan aplikasi perpustakaan ini karena tahapan-tahapannya yang jelas dan terurut. Artinya jika tahapan yang sedang dilakukan belum selesai, maka belum 
bisa lanjut ke tahapan selanjutnya sehingga bisa meminimalisir kesalahan yang terjadi.

\section{Analisa dan Perancangan}

\subsection{Rancangan Sistem}

Perancangan sistem dibuat menggunakan diagam UML (Unified Modeling Language). Terdapat beberapa diagram UML yang digunakan, di antaranya Use Case Diagram dan Activity Diagram (Sukamto \& Shalahuddin, 2013). Rancangan utama aplikasi perpustakaan digambarkan menggunakan use case diagram yang ditunjukkan pada Gambar 1.

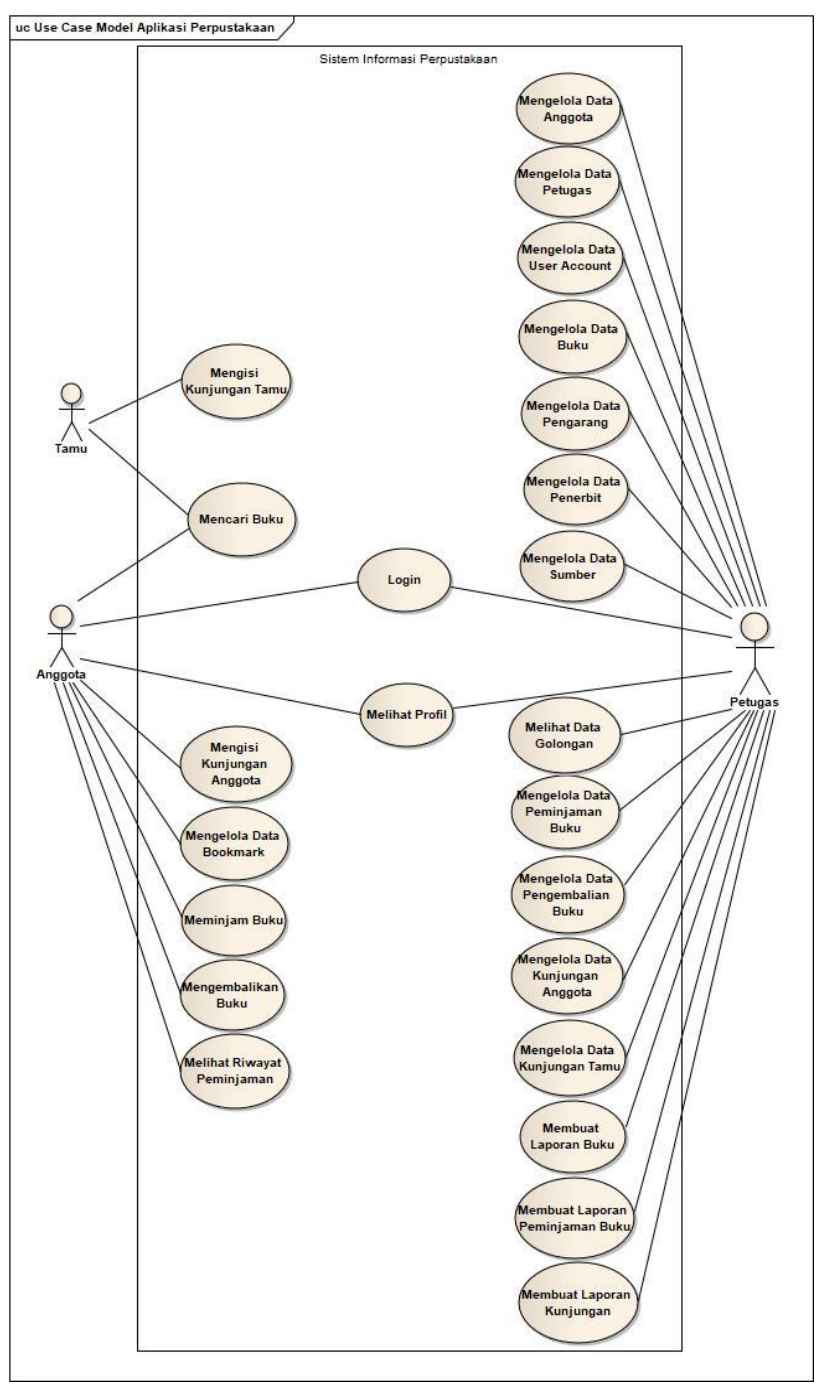

Gambar 1 Use Case Diagram Aplikasi Perpustakaan

Keterangan gambar:

1. Use Case: Login; Actor yang menggunakan fungsi login adalah Petugas dan Anggota; Deskripsi: Untuk melakukan login, Petugas atau Anggota mengisi form login dengan memasukkan username dan password sesuai yang telah disimpan dalam sistem. Kemudian menekan tombol login agar dapat mengelola data-data perpustakaan. Anggota dan Petugas yang login akan diberikan hak akses sesuai aturan yang telah ditetapkan.

2. Use Case: Mencari Buku; Actor: Tamu, Anggota; Deskripsi: Tamu dan Anggota memasukkan keyword dan memilih kategori lalu menekan tombol cari buku untuk mengakses pencarian buku.

3. Use Case: Mengelola Data Buku; Actor: Petugas; Deskripsi: Petugas mengakses data buku dengan menampilkan, menambahkan, mengubah dan menghapus data buku.

\subsection{Rancangan Activity Diagram}

Untuk menggambarkan proses bisnis (aliran kerja) dalam setiap use case maka dibuatkan diagram aktifitas (activity diagram). Beberapa activity diagram dari aplikasi perpustakaan yang akan dikembangkan ditunjukkan pada Gambar 2 sampai Gambar 4.

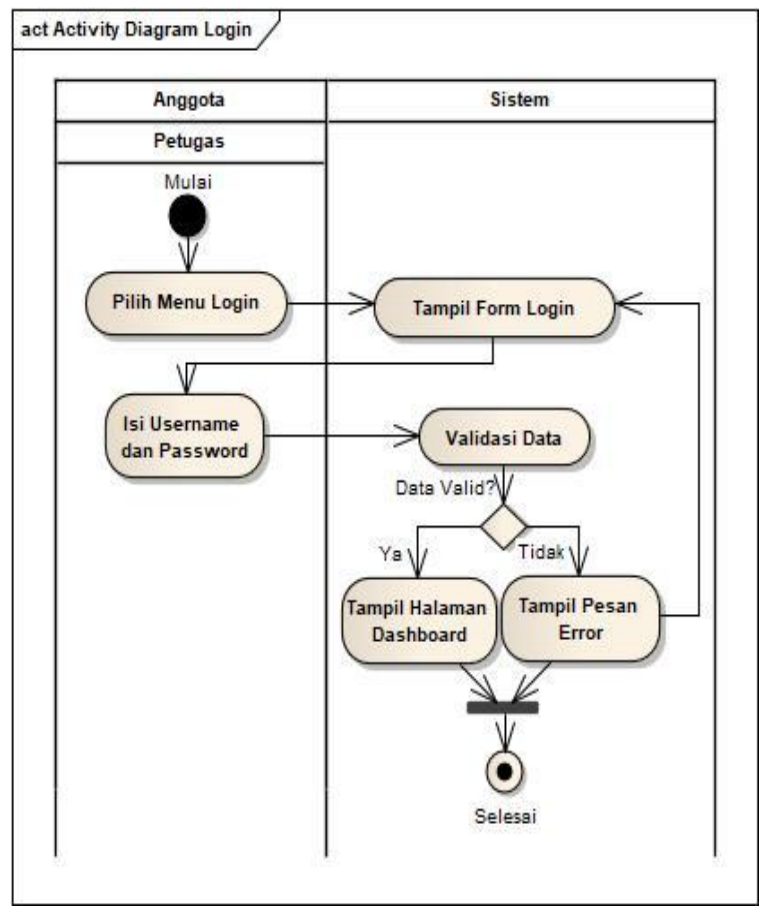

Gambar 2 Activity Diagram Login

Gambar 2 merupakan activity diagram login. Pada halaman utama SkensaLibrary, petugas atau anggota memilih menu login lalu sistem menampilkan form login. Petugas atau anggota memasukkan username dan password. Sistem memvalidasi data, jika data valid, sistem menampilkan halaman dashboard. Sedangkan 
jika data tidak valid, sistem menampilkan pesan error dan kembali ke form login.

Pada Gambar 3 merupakan activity diagram mencari buku. Anggota atau tamu memilih menu cari buku dan sistem menampilkan form pencarian buku. Anggota atau tamu memasukkan keyword atau kata kunci berdasarkan kategori pencarian. Sistem mengecek ketersediaan data buku. Jika buku tersedia, sistem menampilkan daftar buku yang dicari. Jika buku tidak ditemukan dalam persediaan, sistem menampilkan pesan "buku tidak tersedia".

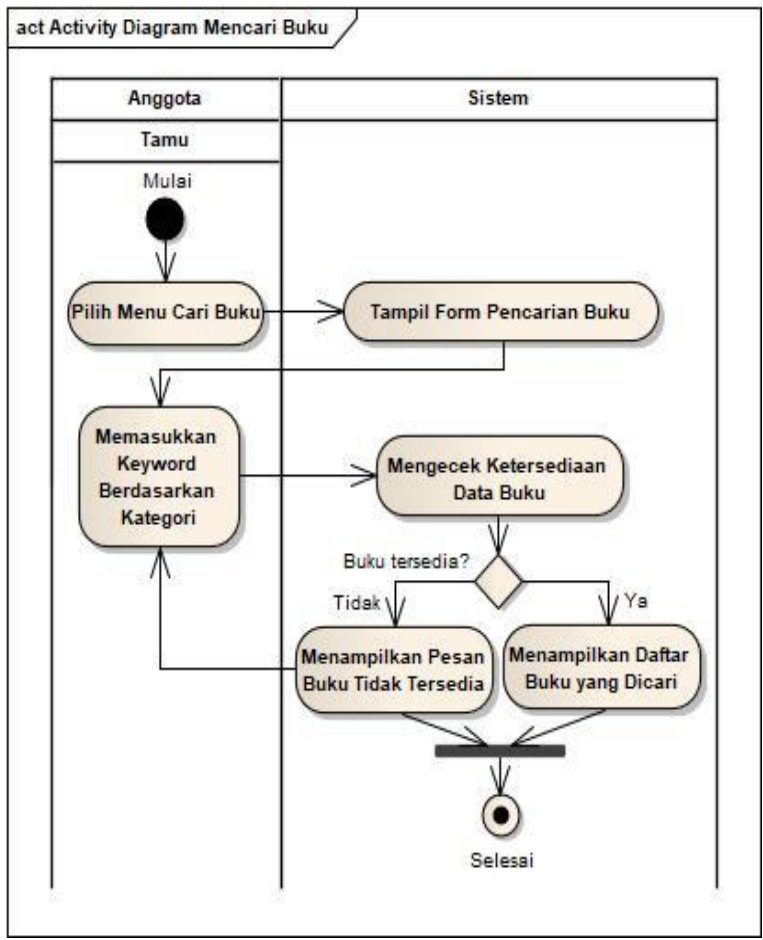

Gambar 3 Activity Diagram Mencari Buku

Pada Gambar 4 merupakan activity diagram mengelola data anggota. Pada halaman dashboard, petugas memilih menu user lalu memilih submenu data anggota, kemudian akan sistem menampilkan form data anggota. Jika ingin menambah data anggota, petugas dapat memilih tombol tambah anggota, sehingga sistem menampilkan form untuk menambah data anggota. Petugas dapat menambahkan data anggota dengan cara mengisi data anggota di form anggota. Ketika disimpan sistem akan melakukan validasi data. Jika data anggota yang dimasukkan belum ada dan masukkannya valid, maka sistem menyimpan data anggota. Setelah berhasil disimpan kemusian ditampilkan di form data anggota. Sedangkan jika data anggota yang dimasukkan tidak valid, maka akan ditempilkan pesan kesalahan dan kembali menampilkan form anggota.

Untuk melakukan perubahan data anggota, petugas dapat memilih/mengklik tombol edit pada form data anggota. Kemudian data anggota akan ditampilkan di form perubahan anggota sehingga petugas dapat mengubah datanya. Setelah dilakukan perubahan dapat disimpan dengan mengklik tombol simpan. Berikutnya sistem akan melakukan validasi, jika hasil validasi menunjukkan bahwa data yang dimasukkan dinyatakan valid, maka sistem akan menyimpan data anggota dan menampilkan di form data anggota. Tetapi jika hasil validasi menunjukkan datanya tidak valid, maka sistem akan menampilkan pesan kesalahan dan kembali menampilkan form anggota. Untuk menghapus data anggota, petugas dapat melakukan dengan memilih tombol hapus sesuai dengan data anggota yang akan dihapus. Setelah dipilih tombol hapus, maka sistem akan menampilkan pesan bahwa data telah dihapus dan sistem menampilkan data anggota.

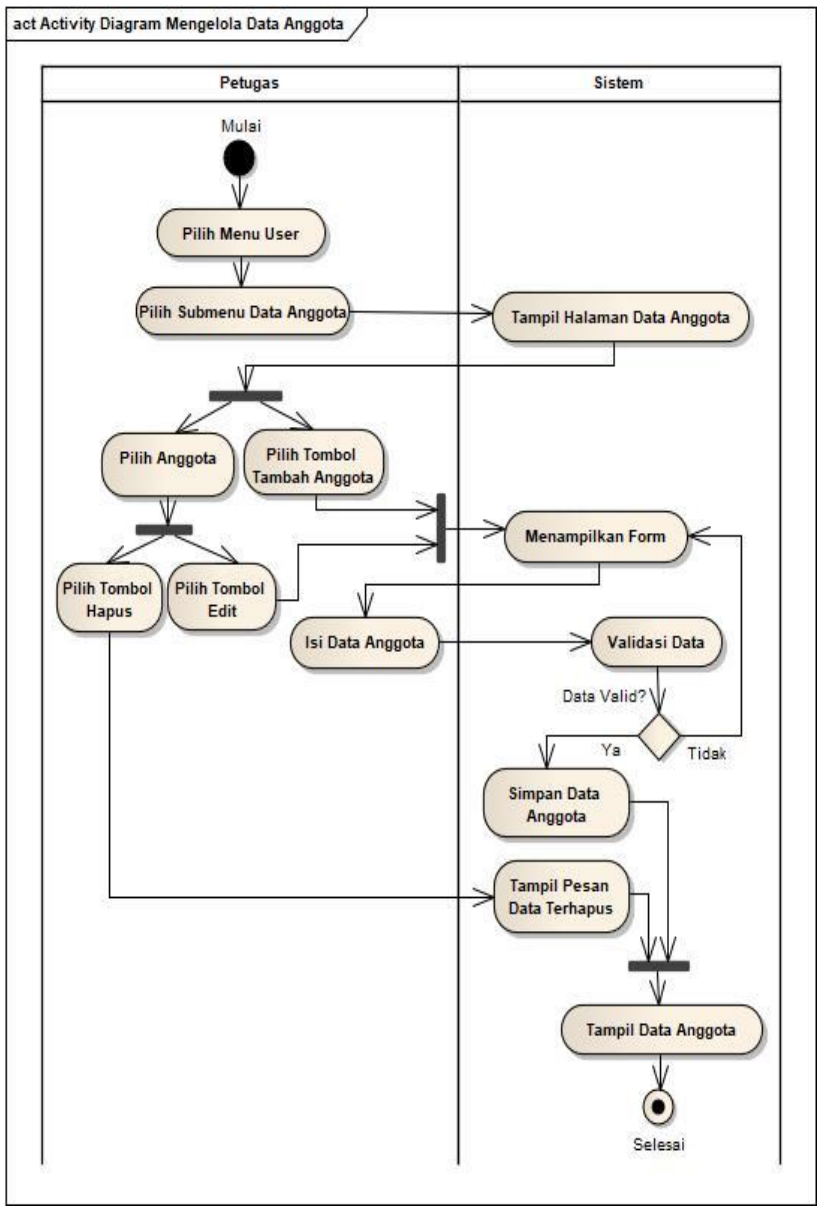

Gambar 4 Activity Diagram Mengelola Data Anggota 


\section{Implementasi dan Pengujian}

\subsection{Perangkat Pendukung}

Dalam pengembangan aplikasi perpustakaan digunakan beberapa perangkat pendukung dengan spesifikasi sebagai berikut:

- Laptop dengan Processor Intel ${ }^{\circledR}$ Celeron ® CPU N3050@1.60 Ghz

- Kapasitas RAM sebesar 2 GB

- Harddisk 500GB

- VGA 1GB

- Keyboard dan Mouse

- Monitor 14 Inch

Sedangkan perangkat lunak pendukung yang digunakan untuk pengembangan aplikasi perpustakaan adalah:

- Sistem Operasi yang terinstal adalah Windows 7

- Jaringan Internet

- Browser yang digunakan Google Chrome.

\subsection{Implementasi}

Implementasi merupakan tahap menerjemahkan spesifikasi sistem ke dalam sistem yang dapat dieksekusi (Sommerville, 2011). Implementasi dapat juga mengkonversi model menjadi source code (Pressman \& Maxim, 2015) atau program yang dapat dieksekusi (Stephens, 2015). Sehingga implementasi adalah menerjemahkan model/desain yang dibuat berdasarkan kebutuhan sistem menjadi source code sehingga terbentuk program komputer yang dapat dieksekusi.

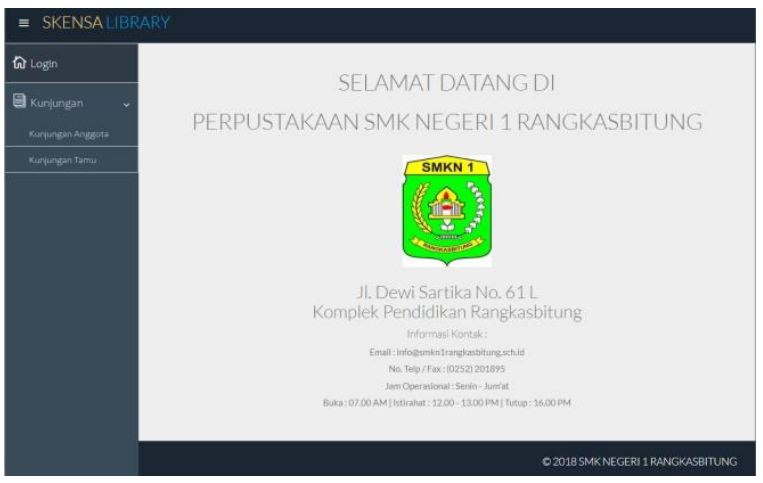

Gambar 5 Halaman Utama

Pada tahap ini dibuat program komputer berdasarkan desain yang telah dirancang sebelumnya. Aplikasi dibuat menggunakan bahasa PHP, sedangkan basis data disimpan dan dikelola menggunakan MySQL. Setelah melakukan tahap pembuatan aplikasi, tahap selanjutnya adalah mendaftarkan domain dan hosting dengan alamat skensalibrary.web.id. Halaman utama dari aplikasi perpustakaan yang telah dibuat ditunjukkan pada Gambar 5.

Sedangkan halaman riwayat peminjaman ditunjukkan pada Gambar 6. Dengan adanya riwayat peminjaman, petugas dapat menelusuri sejarah atau status buku.

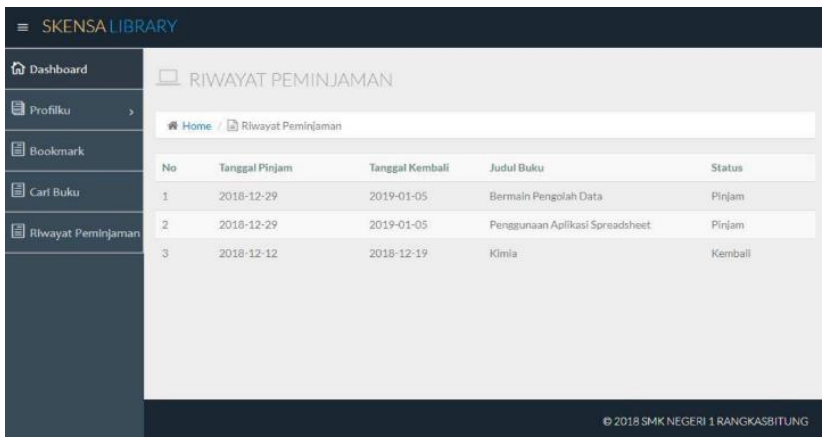

Gambar 6 Halaman Riwayat Peminjaman

\subsection{Pengujian}

Pada aplikasi perpustakaan ini dilakukan pengujian usability (kegunaan) terhadap 20 responden yang terdiri dari 2 guru dan 18 siswa SMK Negeri 1 Rangkasbitung. Pengujian dilakukan dengan cara memberikan lembar kuisioner yang berisi 30 soal berdasarkan USE Questionnaire kepada responden lalu responden mengisi kolom pilihan yang tersedia berdasarkan pendapat masing-masing. Untuk mengetahui tingkat kemudahan penggunaan aplikasi yang dibuat maka perlu dilakukan pengujian/penilaian usability.

Setelah hasil kuisioner direkap, maka dilakukan penghitungan skor total dengan rumus Skor Total/ Skor Maksimal x 100\%. Penghitungan skor total ditampilkan pada tabel 6.1.

Tabel 6. 1 Penghitungan Skor Total

\begin{tabular}{|c|c|c|c|}
\hline Kriteria & Jumlah & Skor & Jumlah $x$ Skor \\
\hline SS & 113 & 5 & 565 \\
\hline S & 374 & 4 & 1496 \\
\hline RG & 98 & 3 & 294 \\
\hline TS & 15 & 2 & 30 \\
\hline STS & 0 & 1 & 0 \\
\hline \multicolumn{3}{|c|}{ Skor Total } & 2385 \\
\hline
\end{tabular}

Dari 30 soal yang diberikan kepada masingmasing responden dihasilkan:

- Jumlah SS = 113 poin sangat setuju

- Jumlah $S=374$ poin setuju

- Jumlah RG $=98$ poin ragu-ragu 
- Jumlah TS $=15$ poin tidak setuju

- Jumlah STS $=0$ poin sangat tidak setuju

Skor maksimal dihitung berdasarkan asumsi jika jumlah semua jawaban soal adalah Sangat Setuju yang diberi skor 5. Maka penghitungan Skor masksimal adalah:

Skor Maksimal $=$ jumlah jawaban $\mathrm{x}$ total soal $\mathrm{x}$

$$
\begin{aligned}
& 5 \\
= & 20 \times 30 \times 5 \\
= & 3000
\end{aligned}
$$
adalah:

Sedangkan untuk menghitung presentase

Presentase

$$
\begin{aligned}
& =2385 / 3000 \times 100 \% \\
& =79,5 \%
\end{aligned}
$$

Berdasarkan penghitungan di atas, maka diperoleh penilaian persentase dengan nilai $79,5 \%$. Nilai persentase tersebut dalam skala kualitatif termasuk dalam kategori "Tinggi" dan dianggap memenuhi aspek usability.

\section{Penutup}

\subsection{Kesimpulan}

Dari pengembangan aplikasi dan analisa yang telah dilakukan, maka dapat dibuat beberapa kesimpulan berikut ini:

a. Aplikasi perpustakaan ini telah dianggap lolos uji kualitas perangkat lunak dan dinyatakan dapat memenuhi aspek usability (kegunaan). Pada penilaian aspek usability di dapat nilai presentase sebesar 79,5\% (tinggi) sehingga dapat mempercepat proses pengolahan data perpustakaan. Aplikasi ini juga dapat menambah dan mengurangi stok buku secara otomatis jika terdapat transaksi peminjaman atau pengembalian buku. Serta dapat menghitung denda jika anggota terlambat melakukan pengembalian.

b. Siswa atau anggota perpustakaan juga dapat mencari buku dengan mudah di mana saja dan kapan saja dengan adanya pencarian buku online. Pencarian buku pada aplikasi perpustakaan ini hanya dengan mengisi kata kunci dan kategori yaitu berdasarkan judul buku, nama pengarang, nama penerbit, tahun terbit atau nomor panggil buku. Ditambah dengan adanya menu bookmark, anggota dapat menyimpan informasi buku yang telah ditandai.

\subsection{Saran}

Berdasarkan implementasi pengembangan sistem dan analisa yang telah dilakukan, maka disarankan untuk beberapa perbaikan untuk pengembangan selanjutnya yaitu:

a. Aplikasi dapat dilengkapi layanan selfservice agar anggota dapat meminjam buku secara mandiri.

b. Aplikasi dapat dilengkapi dengan teknologi RFID (Radio Frequency Identification) untuk jaminan keamanan buku.

\section{References}

Hartono. (2016). Manajemen Perpustakaan Sekolah: Menuju Perpustakaan Modern dan Profesional. Yogyakarta: Ar-Ruzz Media.

Hendrianto, D. E. (2014). Pembuatan Sistem Informasi Perpustakaan Berbasis Website pada Sekolah Menengah Pertama Negeri 1 Donorojo Kabupaten Pacitan. IJNS Indonesian Journal on Networking and Security - Volume 3 No 4 - ijns.org, 57-64.

Pressman, R. S., \& Maxim, B. R. (2015). Software Engineering: A Practitioner's Approach (8th ed.). New York: McGraw-Hill Education.

Shalahuddin, M., \& Sukamto, R. A. (2014). Rekayasa Perangkat Lunak Terstruktur dan Berorientasi Objek (Vol. Cetakan Kedua). Bandung: Informatika.

Sommerville, I. (2011). Software Engineering (9th ed.). Boston: Addison-Wesley.

Stephens, R. (2015). Beginning Software Engineering. Indiana: John Wiley \& Sons, Inc.

Sukamto, R. A., \& Shalahuddin, M. (2013). Rekayasa Perangkat Lunak Terstruktur dan Berorientasi Objek. Bandung: Informatika.

Usada, E., \& Ariyanto. (2012). Rancang Bangun Sistem Informasi Manajemen pada Perpustakaan SMA Negeri 1 Bawang Kabupaten Banjarnegara. Jurnal Telematika Vol. 5 No. 2, 24-35.

Utami, N. P. (2013). Pengembangan Program OPAC (Online Public Access Catalogue) Berbasis Subject Indexing untuk Mempermudah Penelusuran Koleksi Jurnal di Perpustakaan Universitas Pendidikan Ganesha. Jurnal Sains dan Teknologi Vol. 2, No. 1, 151-162. 